\title{
Development of a Real-Time Reverse Transcription Polymerase Chain Reaction Assay for c-myc Expression That Allows the Identification of a Subset of c-myc + Diffuse Large B-Cell Lymphoma
}

\author{
Ana-Isabel Sáez, María-Jesús Artiga, Cristina Romero, Sandra Rodríguez, \\ Juan-Cruz Cigudosa, Alberto Pérez-Rosado, Isabel Fernández, \\ Margarita Sánchez-Beato, Esther Sánchez, Manuela Mollejo, and Miguel Á Piris \\ Centro Nacional de Investigaciones Oncológicas (A-IS, M-JA, CR, SR, J-CC, AP-R, IF, MS-B, MÁP), Madrid, and \\ Hospital Virgen de la Salud (ES, MM), Toledo, Spain
}

SUMMARY: Absence of a reliable method for determining the level of c-myc expression has impeded the analysis of its biological and clinical relevance in tumors. We have standardized the conditions for a real-time reverse transcription polymerase chain reaction analysis for c-myc expression, including the selection of an endogenous reference (18S rRNA), the adequate number of measurements for each sample (2 cDNA in triplicate), and suitable controls for determining inter-and intrarun variability (standard curve and calibrator). Subsequently, in a series of 56 non-Hodgkin's lymphomas, we analyzed the expression of c-myc mRNA, using real-time reverse transcription polymerase chain reaction, and of other functionally related proteins (bcl-6, p27, cyclin D3, and p53). As expected, all eight Burkitt's lymphoma cases analyzed had high levels of c-myc mRNA expression compared with that observed in reactive lymphoid tissue. There was a wider range of expression in diffuse large B-cell lymphoma, with 30\% (15 of 48) of cases overexpressing c-myc. This overexpression was largely independent of c-myc translocations (4 of 5), as demonstrated by fluorescence in situ hybridization. In this large B-cell lymphoma series, a high level of c-myc expression predicted lower survival probability, irrespectively of the International Prognostic Index risk group classification. A slightly increased frequency of p53 inactivation was observed in the cases with c-myc overexpression, which suggests a growth advantage in lymphomas with concurrent deregulation of c-myc and p53. In addition, a moderate increase in bcl-6 protein expression was observed in the c-myc-positive cases, suggesting the existence of a complex interrelationship between these two genes. These findings suggest that c-myc may play a relevant role in the pathogenesis of a subset of large B-cell lymphoma and suggest the existence of additional regulatory mechanisms of c-myc expression to c-myc rearrangements. (Lab Invest 2003, 83:143-152).

$C$ -myc is a multifunctional gene involved in important cellular processes, such as cell proliferation, differentiation, and apoptosis. c-myc targets include critical genes involved in growth, the cell cycle, signaling, and adhesion (eg, cyclin D2, cyclin D3, DP1, p27 ${ }^{\mathrm{KIP} 1}, \mathrm{p} 21^{\mathrm{CIP} 1}, \mathrm{AKT}, \mathrm{Cul}-1, \mathrm{TGFR}-2, \mathrm{CDC} 25 \mathrm{C}, \mathrm{API}$, Bc/ll) (Coller et al, 2000; Eischen et al, 2001; Guo et al, 2000; Nasi et al, 2001; Neiman et al, 2001; Nesbit et al, 2000; O'Hagan et al, 2000; Schuhmacher et al, 2001).

Although c-myc gene was initially described as being involved in $t(8 ; 14)$ in Burkitt's lymphoma (BL), overexpression of c-myc has been found in other solid

\section{DOI: 10.1097/01.LAB.0000057000.41585.FD}

Received December 9, 2002

A-IS and M-JA contributed equally to this work. This study was supported by grants from the Fondo de Investigaciones Sanitarias (FIS 98/993, 01/0035-01), Ministerio de Sanidad y Consumo, and from the Ministerio de Ciencia y Tecnología (1FD97-0421, SAF2001-0060), Spain.

Address reprint requests to: Dr. Miguel Á Piris, Programa de Patología Molecular, Centro Nacional de Investigaciones Oncológicas, c/Sinesio Delgado, 4-12, 28029 Madrid, Spain.E-mail:mapiris@cnio.es tumors such as breast, prostate, and gastrointestinal carcinomas and in melanoma. In these neoplasias, c-myc expression has been shown to be dependent on amplifications of the gene or to be derived from deregulation of upstream genes in the c-myc pathway, such as BRCA1, PTEN, and $\beta$-catenin/APC (Nesbit et al, 1999). In addition, $\mathrm{N}$-myc has been implicated in the pathogenesis of neuroblastomas (Fulda et al, 1999).

c-myc activation is of particular relevance in leukemia and lymphoma. Virtually all BLs show translocation of the c-myc gene with the heavy- or light-chain immunoglobulin (Ig) locus, and most of them also contain somatic mutations (Cesarman et al, 1987; Dalla-Favera et al, 1982; Khaira et al, 1998). Diffuse large B-cell lymphomas (DLBCLs) display c-myc translocations in 1 to $15 \%$ of cases (Cigudosa et al, 1999; Kramer et al, 1998; Vitolo et al, 1998), amplifications in 15\% (Rao et al, 1998), and somatic mutations in 32\% of tumors (Pasqualucci et al, 2001). Translocations and mutations have been linked to c-myc activation in BL and DLBCL because these 
structural alterations were accompanied by an altered pattern of c-myc transcription, specifically the removal of the block on transcriptional elongation (Bradley et al, 1993; Cesarman et al, 1987). Furthermore, regulatory elements of promoters and enhancers of Ig and c-myc genes have been shown to contribute to this deregulation (Gerbitz et al, 1999; Ji et al, 1994; Kanda et al, 2000; Madisen and Groudine, 1994).

Results of expression analyses using Northern blot (Hernandez et al, 1999), in situ hybridization (Greil et al, 1991), and immunohistochemistry (IHC) (Chang et al, 2000; Pagnano et al, 2001) coincide in showing that c-myc overexpression is a common observation in $\mathrm{BL}$ and DLBCL. Despite this, there is striking variability in the reported $c$-myc protein cellular localization and intensity of c-myc expression in reactive and tumoral lymphoid tissue (Chang et al, 2000; Jack et al, 1986; Loke et al, 1988; Pagnano et al, 2001). Despite the significant role that c-myc seems to play in lymphomagenesis, the difficulties for demonstrating c-myc expression at the protein or RNA level has impeded our gaining a deeper understanding of the mechanism regulating c-myc expression and the identification of c-myc targets in lymphoma tumoral specimens. Thus, under these circumstances, recent analyses using real-time RT-PCR of c-myc mRNA expression have demonstrated in breast cancer and other tumors that the level of expression of c-myc is clinically and biologically relevant and that the results are highly reproducible with this technique (Bieche et al, 2001; Bieche et al, 1999; Christoph et al, 1999; Latil et al, 2000).

Interest in c-myc has been fueled by recent results showing that its expression in B cells could be dependent on bcl- 6 and blimp- 1 genes. bcl- 6 protein is a significant transcriptional factor involved in lymphomagenesis and has been proposed as being involved in the transcriptional activation of c-myc promoter through the repression of a c-myc transcriptional repressor, blimp-1 (Lin et al, 1997; Shaffer et al, 2000). Other important targets of c-myc are p27 and cyclin D3, molecules whose interaction plays a critical role in G1/S transition (Bouchard et al, 1999; Sanchez-Beato et al, 1999), and whose abnormal expression has been found to be associated with adverse clinical outcome in DLBCL (Saez et al, 1999). In nonlymphoid tumors, c-myc expression has been described as promoting apoptosis, which explains the high frequency of p53 mutation and apoptosis inactivation in neoplasms characterized by overexpressed c-myc (Teitz et al, 2000; Wagner et al, 1994).

Here we have quantified the level of expression of c-myc mRNA and other hypothetical c-myc targets (bcl-6, p27, cyclin D3) to establish whether the findings in a series of DLBCL corroborate the previous observations in experimental models. At the same time, we have analyzed the status of p53 gene to test whether aggressive B-cell lymphoma with c-myc overexpression experiences a pressure to inactivate the p53 pathway. The results confirm the role of c-myc in DLBCL and suggest the existence of different mechanisms of c-myc deregulation.

\section{Results}

Standardization of Real-Time Reverse Transcription Polymerase Chain Reaction for c-myc mRNA Measurement

For each experimental sample, the amount of the target (c-myc) and endogenous reference (18S rRNA) was determined from the standard curve. This standard curve was composed of five points obtained from 5 -fold serial dilutions $(1 / 5,1 / 25,1 / 125,1 / 625,1 / 3125)$ of cDNA from the Raji cell line, synthesized from 500 ng of total RNA. We considered only experiments in which the linear relationship between $C_{t}$ (threshold cycle) and the log of the amount of standard curve for c-myc and 18S rRNA were higher than 0.98 (correlation coefficient). The c-myc amount was then divided by the amount of $18 \mathrm{~S}$ rRNA to obtain a normalized c-myc value.

18S rRNA was included as an endogenous control gene to correct for variations in the degree of RNA degradation and efficiencies of reverse transcription. Before performing this study, we confirmed that expression of $18 \mathrm{~S}$ rRNA was steady in a series of $\mathrm{BL}$ and DLBCL, including nodal and extranodal localizations, and immunoblastic, centroblastic, and plasmablastic cytologies. To demonstrate the suitability of the $18 \mathrm{~S}$ rRNA gene as control, we used similar amounts of each sample, adjusting the quantity of each c-DNA by electrophoresis in agarose gels and absorbance at $260 \mathrm{~nm}$ and then studied the expression of this gene by real-time reverse transcription polymerase chain reaction (RT-PCR).

To test inter-run variability, we included a calibrator sample (single tonsil cDNA) in each PCR. We evaluated the variability of the technique testing the c-myc expression of this calibrator in every experiment. Thus, the standard deviation (SD) was 0.029, and the coefficient of variation was $13.096 \%$. In addition, for testing intrarun variability in each sample, two cDNAs from each sample and two serial dilutions of each cDNA were analyzed. All samples were measured in triplicate. The measurements were considered to be acceptable when the SD of $C_{t}$ triplicates was lower than 0.38 and when that of serial dilutions was lower than 0.06 .

To determine the cutoff point of altered c-myc gene expression at the RNA level, we scored the mean of expression of reactive lymphoid tissue (0.23). The relative c-myc gene expression in each sample was normalized to this cutoff value to generate the final relative expression levels. Final results, expressed as $\mathrm{n}$-fold differences in c-myc gene expression relative to the cutoff value, termed ${ }^{\mathrm{r}} \mathrm{c}-\mathrm{myc}$ (relative c-myc expression), were determined as follows: ${ }^{r} \mathrm{c}-\mathrm{myc}=$ c-myc sample/c-myc cutoff expression.

\section{c-myc Expression in Reactive Lymphoid Tissues}

c-myc gene expression at the RNA level in lymphoid reactive tissue was determined for six tonsils. The values ranged between 0.20 and 0.36 , with a mean of 0.23 . These values were clearly lower than those 
observed in the BL series analyzed here (ranging from 0.44 to 2.22 ), in a similar ratio to that previously reported in the comparison of reactive tonsils and $B L$ (Hernandez et al, 1999).

\section{c-myc Expression in the LBCL Series}

A summary of the results is included in Table 1. Eight cases of BL were studied. The expression level (measured as ${ }^{\mathrm{r}} \mathrm{c}-\mathrm{myc}$, in relation to the level of expression observed in reactive lymphoid tissue) ranged from 1.47 to 9.50 , with a mean of 3.80 (Table 1; Fig. 1).

c-myc mRNA expression was analyzed in 48 cases of DLBCL, including 34 nodal DLBCLs and 14 extranodal DLBCLs. ' $\mathrm{C}-\mathrm{myc}$ levels had a range from 0.00 to 8.40 , with a mean of 1.14 . Low ${ }^{\mathrm{r}} \mathrm{c}$-myc levels (lower than reactive lymphoid tissue) were observed in $73 \%$ (35 of 48) of cases (26 nodal DLBCLs and 9 extranodal DLBCLs), and high levels were noted in $27 \%$ (13 of 48 ) of cases (8 nodal DLBCLs and 5 extranodal DLBCLs; Table 1; Fig. 1).

Levels of ${ }^{r} \mathrm{c}$-myc expression from $\mathrm{BL}$ were significantly higher than those observed in DLBCL $\left(\chi^{2}=\right.$ 14.221, $p=0.003$, Kruskal-Wallis test). No significant differences between means of ${ }^{r} \mathrm{C}$-myc values were found when comparing nodal DLBCL and extranodal DLBCL cases ( $p>0.05$; Kruskal-Wallis test).

\section{Fluorescence in Situ Hybridization}

It was possible to analyze the presence of rearrangements and amplifications of c-myc gene by fluorescence in situ hybridization (FISH) in eight DLBCL and five $B L$ paraffin-embedded samples (Fig. 2). One of five DLBCL cases with high c-myc expression and one of three DLBCLs with low c-myc expression showed c-myc rearrangements. Four of five BLs analyzed also showed c-myc rearrangements. All of these rearrangements were identified as the translocation $t(8 ; 14)$. We found no amplification of c-myc gene in any case.

\section{Relationship between ${ }^{r} \mathrm{c}$-myc mRNA Expression and MIB1, p53, p27, Cyclin D3, and bcl-6 Protein Expression in DLBCL Cases}

To determine the possible relationship between ${ }^{r} \mathrm{c}$ myc levels and the proliferative activity of these tumors, we examined MIB1 immunohistochemistry expression (Table 1). We found that the percentage of positive cells varied from 55 to 100 (mean: 88.02) in all DLBCL cases available for study. The MIB1 means of the different groups defined by ${ }^{\mathrm{r}} \mathrm{c}-\mathrm{myc}$ values were nearly identical (86.88, and 90.50 for low and high rc-myc levels, respectively; $p>0.05$, Kruskal-Wallis test). No significant correlation was found between 'c-myc and MIB1 expression ( $r$ : 0.082, $p>0.05$, Spearman correlation).

bcl-6 is a transcription factor that has been proposed as playing a role in the regulation of c-myc expression (Shaffer et al, 2001). We examined immunohistochemically the expression levels of bcl-6 in DLBCL cases. bcl- 6 reactivity could be evaluated in
41 cases. Fewer than $20 \%$ of positive cells were found in 7 cases, 10 showed an intermediate level of expression, and 26 cases had more than $80 \%$ positive cells (Table 1). The mean was 67.12, in agreement with previously reported results (Artiga et al, 2002). Mean levels of bcl- 6 expression show a moderate increase in DLBCL cases with high c-myc mRNA expression $\left(\chi^{2}\right.$ $=5.159, p=0.023$, Kruskal-Wallis test; $r=0.324, p<$ 0.05 , Spearman correlation). The relationship between bcl-6 and c-myc expression was not observed in the $\mathrm{BL}$ group ( $p>0.05$, Spearman correlation), but the small size of the group (eight cases) precludes the possibility of reaching a conclusion concerning this relationship.

c-myc overexpression induces cell-cycle progression and apoptosis simultaneously, explaining the increased parallel inactivation of p53 (Wagner et al, 1994) seen in tumoral cell lines and the presence of caspase 8 deletion observed in neuroblastoma and other tumors (Teitz et al, 2000). We tried to establish whether there was a relationship between c-myc expression levels and inactivation of p53 in all of the series. Three cases of 54 showed p53 missense or nonsense mutations or an anomalous p53+/p21phenotype (seven cases; Table 1) (Villuendas et al, 1997). We found that cases with high c-myc expression had a higher probability of being p53-inactivated, but this was not statistically significant.

p27 and cyclin D3 are two important c-myc targets for G1/S transition (Bouchard et al, 1999; Schuhmacher et al, 2001). In addition, it has been reported that cyclin D3 may contribute to p27 inactivation in DLBCL by sequestration into complexes containing CDK4, where p27 is rendered inactive but stabilized and detectable by immunohistochemical techniques (Bouchard et al, 1999; Sanchez-Beato et al, 1999). Confirming these results (data not shown), the expression level of p27 and cyclin D3 in this series showed a strong positive correlation in DLBCL cases $(r=0.416$, $p=0.006$, Spearman test). In these cases, there was no clear correlation between c-myc mRNA levels and p27 protein expression $(r=0.071, p>0.05$, Spearman test) or cyclin D3 ( $r=0.072, p>0.05$, Spearman test), although c-myc-positive cases had a tendency to overexpress p27 $\left(\chi^{2}=2.811, p=0.094\right.$, Pearson test).

\section{Relationship between c-myc mRNA Levels and Clinical Outcome in DLBCL}

In the DLBCL, the Kaplan-Meier plot and long rank test indicated that patients with high ${ }^{\mathrm{r}} \mathrm{c}-\mathrm{myc}$ level had lower overall survival (OS) and failure-free survival (FFS; $p=0.0008$ for OS and $p=0.009$ for FFS; Fig. 3). In addition, a univariate Cox analysis confirmed that high 'c-myc levels were a very good predictor of shorter OS and FFS in the series of patients with DLBCL $(p=0.027$, relative risk $=2.668$ for OS; $p=$ 0.016 , relative risk $=2.940$ for FFS).

The International Prognostic Index (IPI) is a recognized predictor of OS in high-grade lymphomas. In our DLBCL series, the risk defined by the IPI accurately distinguished different survival probabilities $(p=$ 
Table 1. Summary of the Results of c-myc Molecular Alterations (FISH); c-myc mRNA Expression (real-time RT-PCR); MIB1, bcl-6 Protein Expression (IHC); p53 Inactivation; and Clinical Outcome.

\begin{tabular}{|c|c|c|c|c|c|c|c|c|c|c|c|c|}
\hline \multirow[b]{2}{*}{ Case } & \multirow[b]{2}{*}{$\begin{array}{l}\text { Tumoral } \\
\text { cells (\%) }\end{array}$} & \multirow[b]{2}{*}{ Diagnosis } & \multicolumn{2}{|c|}{ c-myc gen } & \multicolumn{2}{|c|}{$\begin{array}{c}\text { c-myc } \\
\text { (RNAm) }\end{array}$} & \multirow[b]{2}{*}{ MIB1 } & \multirow[b]{2}{*}{ bcl6 } & \multicolumn{2}{|l|}{ p53 status } & \multicolumn{2}{|c|}{ OS } \\
\hline & & & Amplif & Rearrang & Value & SD & & & gen & $\mathrm{IHC}$ & $\begin{array}{c}\text { Time } \\
\text { (months) }\end{array}$ & Status \\
\hline 1 & $70 \%$ & DLBCL & & & 0 & & 87 & 37 & ND & Active & 8 & Alive \\
\hline 2 & $70 \%$ & DLBCL & & & 0 & & 95 & 90 & Wt & Active & 69 & Alive \\
\hline 3 & $70 \%$ & DLBCL & & & 0 & & 55 & 37 & Wt & Active & 73 & Alive \\
\hline 4 & $80-100 \%$ & DLBCL & & & 0 & & 74 & 0 & Wt & Active & 53 & Alive \\
\hline 5 & $80-100 \%$ & DLBCL & & & 0 & & 95 & n.a. & Wt & Active & 9 & Dead \\
\hline 6 & $80-100 \%$ & DLBCL & & & 0.19 & 0.024 & 81 & 85 & Wt & Active & 19 & Dead \\
\hline 7 & $70 \%$ & DLBCL & & & 0.26 & 0.085 & 90 & 75 & Wt & Active & 82 & Dead \\
\hline 8 & $80-100 \%$ & DLBCL & - & - & 0.30 & 0.000 & 96 & 85 & Wt & Active & 22 & Dead \\
\hline 9 & $80-100 \%$ & DLBCL & & & 0.34 & 0.120 & n.a. & n.a. & Mt, aa213, R-R & Active & n.a. & n.a. \\
\hline 10 & $80-100 \%$ & DLBCL & - & + & 0.34 & 0.073 & 90 & 90 & Wt & Active & 3 & Dead \\
\hline 11 & $80-100 \%$ & DLBCL & & & 0.36 & 0.090 & 84 & 56 & Wt & Active & n.a. & n.a. \\
\hline 12 & $80-100 \%$ & DLBCL & & & 0.41 & 0.030 & 98 & 95 & Wt & Active & 96 & Dead \\
\hline 13 & $80-100 \%$ & DLBCL & & & 0.45 & 0.030 & 100 & 60 & Wt & Active & n.a. & n.a. \\
\hline 14 & $80-100 \%$ & DLBCL & & & 0.47 & 0.060 & 100 & 95 & ND & Active & 83 & Alive \\
\hline 15 & $80-100 \%$ & DLBCL & & & 0.47 & 0.060 & 81 & 83 & Wt & Active & 58 & Alive \\
\hline 16 & $80-100 \%$ & DLBCL & - & - & 0.50 & 0.060 & 86 & 80 & Wt & Active & 30 & Dead \\
\hline 17 & $60 \%$ & DLBCL & & & 0.51 & 0.024 & 85 & 57 & Wt & Active & 11 & Dead \\
\hline 18 & $60 \%$ & DLBCL & & & 0.51 & 0.059 & 88 & 10 & Wt & Active & 94 & Alive \\
\hline 19 & $80-100 \%$ & DLBCL & & & 0.58 & 0.160 & 92 & n.a. & Wt & n.a. & 33 & Alive \\
\hline 20 & $80-100 \%$ & DLBCL & & & 0.61 & 0.201 & 98 & 3 & Wt & Active & 17 & Dead \\
\hline 21 & $80-100 \%$ & DLBCL & & & 0.64 & 0.060 & 95 & 80 & Wt & Active & 24 & Alive \\
\hline 22 & $80-100 \%$ & DLBCL & & & 0.68 & 0.177 & 82 & 84 & Wt & Active & 87 & Alive \\
\hline 23 & $80-100 \%$ & DLBCL & & & 0.68 & 0.197 & 81 & 56 & Wt & Active & 110 & Alive \\
\hline 24 & $60 \%$ & DLBCL & & & 0.71 & 0.242 & 85 & 87 & Wt & Active & 64 & Alive \\
\hline 25 & $80-100 \%$ & DLBCL & & & 0.72 & 0.149 & 82 & n.a. & Wt & Active & 4 & Dead \\
\hline 26 & $80-100 \%$ & DLBCL & & & 0.75 & 0.171 & 90 & n.a. & Wt & Active & 9 & Dead \\
\hline 27 & $70 \%$ & DLBCL & & & 0.79 & 0.090 & 85 & 9 & Wt & Active & 82 & Alive \\
\hline 28 & $60 \%$ & DLBCL & & & 0.79 & 0.090 & 90 & 90 & Mt, aa239, N-D & Inactive & n.a. & n.a. \\
\hline 29 & $80-100 \%$ & DLBCL & & & 0.83 & 0.335 & n.a. & n.a. & Wt & Active & n.a. & n.a. \\
\hline 30 & $80-100 \%$ & DLBCL & & & 0.87 & 0.149 & 80 & 5 & Wt & Active & 4 & Dead \\
\hline 31 & $80-100 \%$ & DLBCL & & & 0.88 & 0.030 & 97 & 64 & Wt & Active & 3 & Dead \\
\hline 32 & $80-100 \%$ & DLBCL & & & 0.93 & 0.354 & 73 & 95 & Wt & Inactive & 48 & Alive \\
\hline 33 & $80-100 \%$ & DLBCL & & & 0.96 & 0.671 & 82 & 100 & Wt & Active & 77 & Alive \\
\hline 34 & $70 \%$ & DLBCL & & & 0.98 & 0.000 & 85 & 2 & Wt & Active & n.a. & n.a. \\
\hline 35 & $70 \%$ & DLBCL & & & 1.00 & 0.233 & 85 & 10 & Wt & Active & 80 & Alive \\
\hline 36 & $80-100 \%$ & DLBCL & & & 1.01 & 0.098 & 98 & 39 & Wt & Active & 3 & Dead \\
\hline 37 & $80-100 \%$ & DLBCL & & & 1.26 & 0.090 & 80 & 83 & Wt & Active & 3 & Dead \\
\hline 38 & $70 \%$ & DLBCL & & & 1.32 & 0.060 & 78 & 48 & Wt & Inactive & 3 & Dead \\
\hline 39 & $60 \%$ & $\mathrm{BL}$ & - & + & 1.47 & 0.090 & 100 & 82 & Wt & Active & 81 & Alive \\
\hline 40 & $80-100 \%$ & DLBCL & & & 1.65 & 0.030 & 95 & 84 & Wt & Active & 29 & Dead \\
\hline 41 & $80-100 \%$ & $\mathrm{BL}$ & & & 1.88 & 0.124 & n.a. & n.a. & Wt & Active & 1 & Dead \\
\hline 42 & $80-100 \%$ & DLBCL & - & - & 1.92 & 1.471 & 82 & 98 & Wt & Active & n.a. & n.a. \\
\hline 43 & $80-100 \%$ & DLBCL & - & - & 1.92 & 0.359 & 98 & 95 & Wt & Active & 28 & Dead \\
\hline 44 & $80-100 \%$ & DLBCL & & & 1.97 & 0.592 & 90 & 98 & Mt, aa234, Y-Stop & Inactive & 17 & Dead \\
\hline 45 & $80-100 \%$ & DLBCL & - & - & 2.12 & 0.209 & 83 & 80 & Wt & n.a. & 72 & Alive \\
\hline 46 & $80-100 \%$ & $\mathrm{BL}$ & - & + & 2.28 & 0.610 & 100 & 98 & Wt & Inactive & 1 & Dead \\
\hline 47 & $70 \%$ & DLBCL & & & 2.41 & 0.508 & 78 & n.a. & Wt & Active & 3 & Dead \\
\hline 48 & $80-100 \%$ & DLBCL & - & - & 2.95 & 0.359 & 95 & 100 & Wt & Inactive & 34 & Alive \\
\hline 49 & $80-100 \%$ & $\mathrm{BL}$ & - & + & 3.08 & 0.060 & 100 & 100 & Wt & Active & 10 & Alive \\
\hline 50 & $70 \%$ & DLBCL & & & 3.10 & 1.552 & 96 & 80 & Mt, aa213, R-R & Active & 1 & Dead \\
\hline 51 & $80-100 \%$ & $\mathrm{BL}$ & - & - & 3.12 & 1.552 & 100 & 80 & Wt & Active & 25 & Dead \\
\hline 52 & $80-100 \%$ & $\mathrm{BL}$ & & & 4.47 & 0.164 & 100 & 47 & Wt & Active & 60 & Alive \\
\hline 53 & $80-100 \%$ & $\mathrm{BL}$ & & & 4.66 & 2.652 & 100 & 95 & Wt & n.a. & 11 & Alive \\
\hline 54 & $80-100 \%$ & DLBCL & - & + & 6.88 & 0.816 & 98 & 90 & Mt, aa248, R-Q & Inactive & 58 & Alive \\
\hline 55 & $80-100 \%$ & DLBCL & & & 8.40 & 2.850 & 87 & 91 & Wt & Active & 9 & Dead \\
\hline 56 & $80-100 \%$ & $\mathrm{BL}$ & - & + & 9.51 & 3.423 & 100 & 31 & Wt & Active & 71 & Alive \\
\hline
\end{tabular}




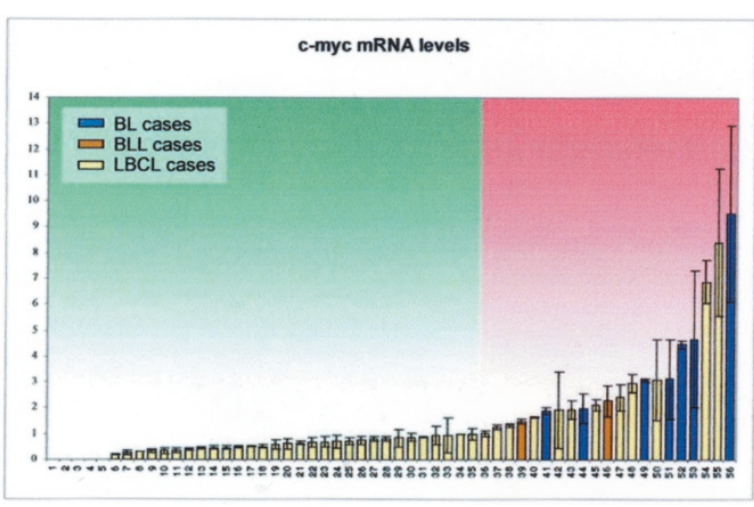

Figure 1.

The histogram shows the ${ }^{\mathrm{r}} \mathrm{c}$-myc mRNA expression levels in diffuse large B-cell lymphomas (DLBCL) cases (yellow bars) and BL (blue bars). Eight DLBCL cases were in the range of c-myc expression of Burkitt's lymphoma (BL). Red background represents area of positive c-myc expression, using the mean of c-myc expression in reactive lymphoid tissue as a threshold. BL-like cases were considered for practical purposes as BL.

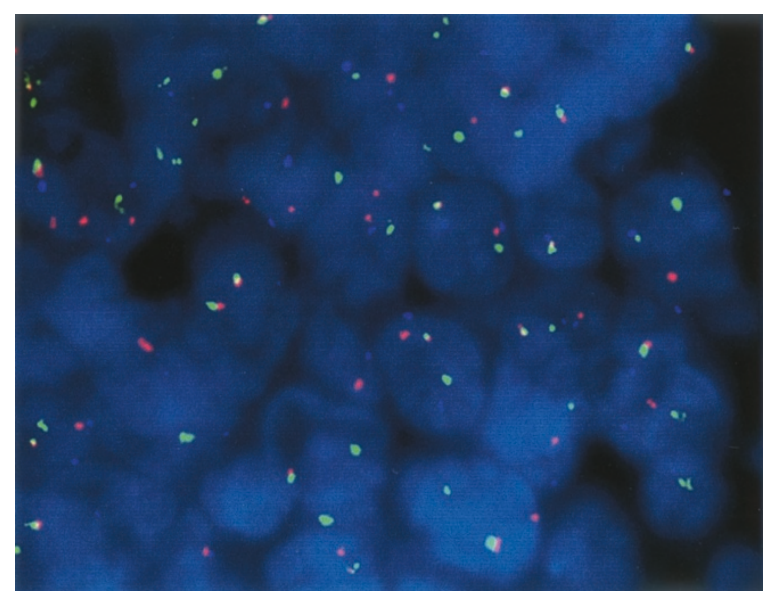

Figure 2.

Detection of $\mathrm{t}(8 ; 14)$ by fluorescence in situ hybridization in a DLBCL sample. Green signals correspond to Ig heavy chain probes, red signals correspond to c-myc probes, and blue signals identified centromere of chromosome 8.

0.043, long rank test for OS; Fig. 3). To determine whether the effect of c-myc in the survival probability was independent of the IPI, we compared the survival probability in the groups of high- and low-risk patients. c-myc expression was an adverse prognostic factor in both groups (Fig. 3), although this was significant only in the group of cases in the high-risk category $(p=$ 0.044 , long rank test for OS).

\section{Discussion}

c-myc mRNA expression in this series of DLBCL is variable, over a range that includes a level of expression similar to that observed in BL. Reliable determination of the c-myc expression has been made possible by the use of real-time RT-PCR, as has been described in previous reports, where c-myc deregulation, as determined by real-time RT-PCR, was associated with larger tumor size and higher histological grade in breast cancer and increased c-myc gene copy numbers in bladder cancer (Bieche et al, 1999; Christoph et al, 1999).

Analysis of c-myc expression using real-time PCR, as performed in this study, benefits from the use of multiple controls, which guarantee the reproducibility of the measurements. We previously found that the endogenous control provided by the 18S rRNA level was independent of growth fraction, morphology, and tumoral localization in this series of DLBCL and BL. In addition, the use of different dilutions of the replicates allowed the identification of variations in the expression level dependent on reverse transcription efficiency and polymerase potential inhibition.

Most of our results confirm previous reports using Northern blot, IHC, and in situ hybridization (Chang et al, 2000; Greil et al, 1991; Hernandez et al, 1999; Pagnano et al, 2001), which showed that a subset of DLBCLs expressed a high level of c-myc, stimulating interest in reproducible immunohistochemical techniques, which could facilitate the analysis of c-myc expression in the future. Although different groups have striven to demonstrate c-myc expression by IHC, the results obtained differed in the expression pattern in normal tissues, subcellular localization, percentage of DLBCL cases with increased expression, and even the intensity of expression in BL (Chang et al, 2000; Jack et al, 1986; Loke et al, 1988; Pagnano et al, 2001). Our own experience with IHC for demonstrating c-myc expression is that results vary greatly depending on the chosen antibody and on other unknown factors. This prompted us to look for alternative tools for measuring c-myc expression, such as real-time RT-PCR.

The results described here raise a number of questions about the clinical significance, mechanisms of c-myc deregulation, and relation with other cell cycle and apoptosis-regulator genes. Thus, considering patients with DLBCL, previous results obtained with IHC techniques showed that a high level of c-myc expression was associated with unfavorable IPI (Chang et al, 2000) and a relatively worse response to chemotherapy (Pagnano et al, 2001). We may now observe that deregulation of c-myc mRNA expression is associated with an adverse clinical course irrespective of the IPI scores. Although posttranslational changes (ie, somatic mutations in Thr 58 and Ser 62 [Gregory and Hann, 2000]) may contribute to the deregulation of the expression level of c-myc, the data shown here indicate that c-myc deregulation seems to play a significant role in the pathogenesis of a subset of $\mathrm{LBCL}$ cases.

Our observations underline the need to take into account mechanisms of c-myc deregulation other than translocations, which were absent in the majority of the DLBCL series and, specifically, in a subset of the cases with a high level of c-myc expression. Additional mechanisms of c-myc deregulation include exon 1-intron 1 somatic mutations and activation of upstream genes (Bradley et al, 1993; Cesarman et al, 1987; Gerbitz et al, 1999; Kanda et al, 2000; Pasqualucci et al, 2001; Wittekindt et al, 2000). It has been claimed that bcl- 6 gene regulates c-myc transcription through 

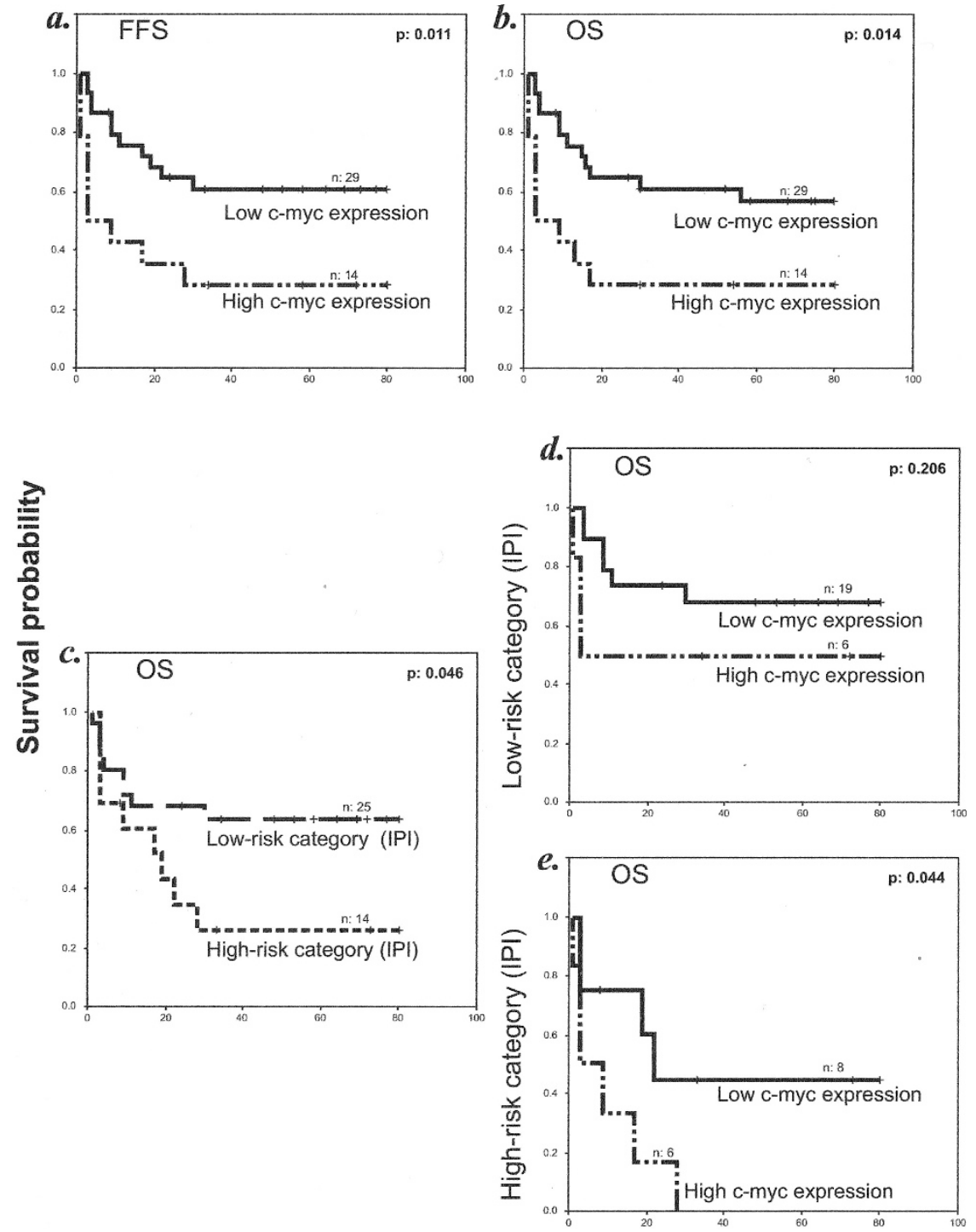

\section{Survival time (months)}

\section{Figure 3.}

Survival plots for DLBCL patients, according to c-myc expression. Patients with a high c-myc expression level had significantly shorter overall survival (OS; a) and failure-free survival (FFS; b). International Prognostic Index (IPI) distinguished two categories of patients, in terms of OS (c). High c-myc expression is associated with shorter survival in the low-risk group (d) and in the high-risk group (e), as defined by IPI, although the impact of c-myc is only significant in the latter group of patients.

the repression of a c-myc transcriptional repressor, blimp-1 (Lin et al, 1997; Shaffer et al, 2000). In this series of cases, we observed a weak relationship between the expression levels of c-myc and bcl-6 that could suggest a link between them. Nevertheless, the nature of the relationship between these two factors seems to be more complex than expected and demands additional experimental analysis (Shaffer et al, 2001).

c-myc is a multifunctional gene, and its pleiotropic effect is dependent on the cellular context. In addition, tumoral cells accumulate alterations that allow themselves to avoid c-myc-induced apoptosis (Felsher et al, 2000). In animal models, it has been shown that loss of ARF and/or p53 reduces apoptosis in B cells that express $E_{\mu}$-myc (Eischen et al, 1999; Schmitt et al, 1999). We found that expression of c-myc was associated with an increased frequency of p53 inactivation in DLBCL cases, thus complementing the similar observations made in other tumor types (Teitz et al, 2000) and confirming preliminary IHC results on DLBCL (Chang et al, 2000). Furthermore, our results prompted us to analyze the potential effects of c-myc deregulation on cell proliferation and on p27 and cyclin D3 (Bouchard et al, 1999; Schuhmacher et al, 2001). Cases with high levels of c-myc expression showed a weak increase in the proliferative index, although this difference was not significant. It is well accepted that p27 and cyclin D3 in particular are targets of c-myc in lymphoid tissue. However, the analysis of our data showed only a relatively weak relation. We interpreted this as indicating the multiplicity of genes in pathways converging at p27. First, 
c-myc controls p27 expression at the transcriptional and posttranscriptional level through mechanisms including transcriptional repression, degradation, and stabilization of complexes that contain cyclin D3 and p27 (Bouchard et al, 1999; O'Hagan et al, 2000; Perez-Roger et al, 1999; Sanchez-Beato et al, 2001; Schuhmacher et al, 2001; Yang et al, 2001). The balance between these signals is also tissue- and cell type-dependent and may significantly rely on p53 mutations or other critical cellular events. In addition, the variability in p27 expression in cases with similar c-myc expression suggests the existence of complex multiple upregulatory genes that may well control p27 expression, such as bcl-6 (Shaffer et al, 2000).

In conclusion, real-time RT-PCR for c-myc allows the reproducible estimation of $\mathrm{c}-\mathrm{myc}$ levels that, when analyzed in a series of DLBCLs, confirms the clinical and biological significance of c-myc expression and suggests the existence of a variety of mechanisms for deregulating this gene.

\section{Materials and Methods}

\section{Tissue Samples, Patients, and Clinical Variables}

Fifty-six samples of tumor specimens from 48 DLBCLs and 8 BLs were selected from the CNIO Tumor Bank Network, CNIO (Madrid, Spain), on the basis of the availability of paraffin-embedded and frozen tissue for molecular studies, and the existence of an adequate clinical follow-up. We also selected six routine reactive tonsils, as representative of reactive lymphoid tissue. Diagnostic pretreatment samples were analyzed in all cases. Tumors were diagnosed according to the World Health Organization classification (Jaffe et al, 2001).

All patients were treated with chemotherapy regimens that included anthracyclins. Follow-up data were available in 49 of 56 cases. Periods of clinical follow-up of patients who were alive at the time of the study ranged from 12 to 110 months (mean: 62.68 months). Age, clinical stage, performance status, lactate dehydrogenase (LDH), and the number of involved extranodal sites were used as outcome criteria, as set out in the IPI (The International Non-Hodgkin's Lymphoma Prognostic Factors Project, 1993). Patients with 0 to 2 unfavorable variables were considered as being low risk, and those with 3 to 5 variables were considered as being high risk. Treatment outcome was measured using FFS and OS. FFS was defined as the time from diagnosis to the first occurrence of progression, relapse after response, or death from any cause. OS was measured from diagnosis to death from any cause. To help in the validation of the kinetic quantitative RT-PCR method, we also analyzed the Raji cell line, obtained from the American Tissue Type Culture Collection (Rockville, Maryland).

\section{Real-Time RT-PCR}

RNA Extraction and c-DNA Synthesis. Total RNA was extracted from frozen sections by the standard Trizol protocol, using TRIzol reagent (GIBCO BRL,
Paisley, Scotland). Electrophoresis on agarose gels and absorbance measurement at $260 / 280 \mathrm{~nm}$ determined the quality of the RNA samples. Before RNA extraction, frozen sections of the specimens were analyzed to ensure that they were representative of the tumor. The percentage of tumoral cells was $>60 \%$ in all cases.

Reverse transcription of RNA was done in a final volume of $20 \mu$ l containing $1 \times$ RT-PCR buffer, 40 units of RNAsin (a RNase inhibitor), 10 units of AMV reverse transcriptase, $50 \mathrm{ng}$ of random hexamers (Promega, Madison, Wisconsin), and $500 \mathrm{ng}$ of total RNA. The samples were denatured at $65^{\circ} \mathrm{C}$ for 5 minutes and incubated at $25^{\circ} \mathrm{C}$ for 7 minutes and $42^{\circ} \mathrm{C}$ for 60 minutes. Afterward, they were heated at $70^{\circ} \mathrm{C}$ for 15 minutes and cooled at $4^{\circ} \mathrm{C}$ to inactivate reverse transcriptase.

Real-Time RT-PCR. c-myc mRNA expression was measured by real-time quantitative RT-PCR using TaqMan technology. The principle of these methods has been described in detail elsewhere (Gibson et al, 1996; Heid et al, 1996). All PCR reactions were performed with the TaqMan Universal PCR Master Mix (PE Applied Biosystems), c-myc and 18S rRNA primers and probes supplied by Applied Biosystems as predeveloped assay reagents in a $25-\mu$ l final reaction mixture, according to the manufacturer's instructions. The thermal cycling conditions were composed of an initial denaturation step at $50^{\circ} \mathrm{C}$ for 2 minutes and $95^{\circ} \mathrm{C}$ for 10 minutes followed by 40 cycles consisting of 15 seconds of denaturation at $95^{\circ} \mathrm{C}$ and 1 minute at $60^{\circ} \mathrm{C}$ for hybridization of the probe and primers.

\section{Immunostaining Techniques}

The bcl-6 protein was detected with monoclonal antibody (MAb) for P6-B6p, a recombinant protein corresponding to amino acids 3 to 484 from DAKO (Glostrup, Denmark; 1/10). p27 protein was detected with a MAb from Transduction Laboratories (Lexington, Kentucky), K25020 (1/1000), generated against the full-length mouse KIP1 protein. cyclin D3 was detected with MAb DCS-22 from Novocastra (Newcastle upon Tyne, UK; 1/10). The proliferation index was evaluated using nuclear antigen Ki67 expression, detected with the MIB1 antibody from Immunotech (Marseille, France). p53 protein was detected with MAb DO7 (Novocastra; 1/50 dilution), generated against recombinant p53 protein, which recognizes both wild-type and mutant forms of p53 protein. p21 WAF1 protein was detected by WAF1 (Ab-1; Oncogene Science, Cambridge, Massachusetts) mouse MAb (1/25 dilution) raised against recombinant human p2 $1^{\text {WAF1 }}$ protein.

Immunostaining techniques were performed in paraffin-embedded tissue sections. For antigen retrieval, before incubation with the antibodies, the slides were heated in a pressure cooker for 3 minutes in $0.01 \mathrm{M}$ sodium citrate solution. In the case of bcl-6 protein detection, the slides were also subsequently digested with proteinase $\mathrm{K}$ for 10 minutes at room temperature. 
After incubation with the primary antibodies, immunodetection was performed with biotinylated anti-mouse immunoglobulins, followed by peroxidase-labeled streptavidin (LSAB-DAKO) and diaminobenzidine chromogen as substrate. All immunostaining was performed using the Techmate 500 (DAKO) automatic immunostaining device.

Incubations omitting the specific antibodies or with unrelated antibodies were carried out to provide controls of the technique. Expression in small lymphocytes was used as an internal control of immunostaining of bcl-6 and p27. Internal controls for cyclin D3 were provided by the degree of staining of endothelial cells and macrophages. Cases that lacked internal controls were excluded from the series. This technique for demonstrating bcl-6 protein expression had previously been validated and found to match the results of bcl- 6 mRNA expression as measured by real-time RT-PCR (Artiga et al, 2002).

\section{Quantitative Studies}

All scoring and interpretations of immunohistochemical results were carried out without knowledge of the clinical variables or results of the molecular analysis.

High-magnification fields were chosen for the evaluation of all of the proteins studied, focusing on tumoral areas and counting up to 300 cells. Scoring of p53 and p21 expression was performed semiquantitatively. We subdivided cases into three different groups according to the number of positive cells (negative [-], positive $[+]$, and highly positive $[++]$ ). Expression of bcl-6, p27, cyclin D3, and MIB1 was scored quantitatively as the percentage of positive cells. All immunoreactive cells were considered to be positive. A manual cell-counting procedure was used so that all nontumoral subpopulations could be excluded on the basis of their cell morphology.

The functionality of p53 protein was evaluated taking into consideration the expression of itself and its effector p21. Cases with p53-/p21- or p53++/p21were considered to have an inactive p53 protein (Villuendas et al, 1997).

The mean values of p27 and cyclin D3 in our series ( $27 \%$ and $44 \%$, respectively) were chosen as the threshold of reactivity for those proteins. These are approximately equivalent to the level of expression of p27 and cyclin D3 within the germinal centers and have been previously reported as being reproducible (Saez et al, 1999; Sanchez-Beato et al, 1999). bcl-6 expression was considered as a continuous variable.

\section{Mutational Analysis of p53 Gene}

Exons 5 to 8 of the p53 gene were amplified from genomic DNA, extracted from tissue samples, using previously described primers and conditions in 54 of the 56 cases in this series (Sanchez-Beato et al, 2001; Villuendas et al, 1997). PCR products were purified using the Microcon PCR system (Millipore Corporation, Bedford, Massachusetts). Direct sequencing of purified PCR products was performed with an auto- mated DNA Sequencer ABI PRISM 3700 Genetic Analyzer (Applied Biosystems, Weiterstadt, Germany). Partial results of p53 sequencing (23 of 56 cases) in this series have been published previously (SanchezBeato et al, 2001; Villuendas et al, 1997).

\section{FISH}

FISH analysis was performed on paraffin-embedded samples. The fluorescently labeled DNA probes were purchased from Vysis (Downers Grove, Illinois). The LSI Ig heavy chain/myc CEP 8, tricolor probe is designed to detect the juxtaposition of the Ig heavy chain locus and myc gene region sequences and also to detect any amplification of the c-myc gene. The CEP 8 probe was used as the control to determine the copy number for chromosome 8 . The probe extends approximately $400 \mathrm{~kb}$ upstream of c-myc and approximately $350 \mathrm{~kb} 3$ ' beyond the gene.

After being deparaffinized and rehydrated, the slides were treated with EDTA ( $1 \mathrm{~mm}, \mathrm{pH} 8)$ for 2 to 3 minutes, then with a pepsin solution $(0.1 \mathrm{~mm} \mathrm{HCl}, 0.05$ $\mathrm{mg} / \mathrm{ml}$ pepsin), and finally dehydrated and denatured in the presence of the probe on a plate at $75^{\circ} \mathrm{C}$ for 2 minutes. Finally, the slides were counterstained with DAPI in an antifade solution.

We established the cutoff values to avoid falsepositive cases by scoring 800 nuclei from four different tonsil samples. The cutoff value was set at $18 \%$. Cases with fusion signals greater than that value were considered positive for the translocation. At least 200 interphase nuclei were analyzed for each case. Cell images were captured using a CCD camera (Photometrics Sensys camera) connected to a computer running the Chromofluor Image Analysis system (Сytovision; Applied Imaging Ltd., New Castle, United Kingdom)

\section{Statistical Analysis}

Relationships between variables were investigated using the Pearson test for categorical variables, the Kruskal-Wallis test for single-ranked data, or the Spearman correlation for double-ranked data. The prognostic value of c-myc expression was evaluated by standard survival analysis, using the Kaplan-Meier method, long rank test, and Cox regression. All statistical analyses were performed using SPSS 10.0 for Windows (SPSS Inc., Chicago, Illinois).

\section{Acknowledgements}

We thank Teresa Flores from the Hospital Clínico, Salamanca; Máximo Fraga from the Complejo Hospitalario Universitario, Santiago de Compostela; Consuelo Pérez from the Toledo Provincial Hospital; Manuel Medina from Hospital del la Merced, Osuna; and María-José Fernández Aceñero from Móstoles Hospital, Madrid, for their kind contribution of tumor samples. We extend our appreciation to Dr. AJ SáezCastillo of Jaén University, Spain, for his help in designing the statistical analyses. 


\section{References}

Artiga MJ, Sáez A, Cristina R, Sánchez-Beato $M$, Mateo $M$, Navas C, Mollejo M, and Piris M (2002). A short mutational hot spot in the first intron of BCL-6 is associated with increased BCL-6 expression and with longer overall survival in large B-cell lymphomas. Am J Clin Pathol 160:1371-1380.

Bieche I, Franc B, Vidaud D, Vidaud $M$, and Lidereau $R$ (2001). Analyses of MYC, ERBB2, and CCND1 genes in benign and malignant thyroid follicular cell tumors by realtime polymerase chain reaction. Thyroid 11:147-152.

Bieche I, Laurendeau I, Tozlu S, Olivi M, Vidaud D, Lidereau R, and Vidaud M (1999). Quantitation of MYC gene expression in sporadic breast tumors with a real-time reverse transcription-PCR assay. Cancer Res 59:2759-2765.

Bouchard C, Thieke K, Maier A, Saffrich R, Hanley-Hyde J, Ansorge W, Reed S, Sicinski P, Bartek J, and Eilers M (1999). Direct induction of cyclin D2 by Myc contributes to cell cycle progression and sequestration of p27. EMBO J 18:53215333.

Bradley JF, Rothberg PG, Ladanyi M, and Chaganti RS (1993). Hypermutation of the MYC gene in diffuse large cell lymphomas with translocations involving band 8q24. Genes Chromosom Cancer 7:128-130.

Cesarman E, Dalla-Favera R, Bentley D, and Groudine M (1987). Mutations in the first exon are associated with altered transcription of c-myc in Burkitt lymphoma. Science 238: 1272-1275.

Chang CC, Liu YC, Cleveland RP, and Perkins SL (2000). Expression of c-Myc and p53 correlates with clinical outcome in diffuse large B-cell lymphomas. Am J Clin Pathol 113:512-518.

Christoph F, Schmidt B, Schmitz-Drager BJ, and Schulz WA (1999). Over-expression and amplification of the c-myc gene in human urothelial carcinoma. Int J Cancer 84:169-173.

Cigudosa JC, Parsa NZ, Louie DC, Filippa DA, Jhanwar SC, Johansson B, Mitelman F, and Chaganti RS (1999). Cytogenetic analysis of 363 consecutively ascertained diffuse large B-cell lymphomas. Genes Chromosom Cancer 25:123-133.

Coller HA, Grandori C, Tamayo P, Colbert T, Lander ES, Eisenman RN, and Golub TR (2000). Expression analysis with oligonucleotide microarrays reveals that MYC regulates genes involved in growth, cell cycle, signaling, and adhesion. Proc Natl Acad Sci USA 97:3260-3265.

Dalla-Favera R, Bregni M, Erikson J, Patterson D, Gallo RC, and Croce CM (1982). Human c-myc onc gene is located on the region of chromosome 8 that is translocated in Burkitt lymphoma cells. Proc Natl Acad Sci USA 79:7824-7827.

Eischen CM, Weber JD, Roussel MF, Sherr CJ, and Cleveland JL (1999). Disruption of the ARF-Mdm2-p53 tumor suppressor pathway in Myc-induced lymphomagenesis. Genes Dev 13:2658-2669.

Eischen CM, Woo D, Roussel MF, and Cleveland JL (2001). Apoptosis triggered by Myc-induced suppression of $\mathrm{Bcl}-\mathrm{X}(\mathrm{L})$ or Bcl-2 is bypassed during lymphomagenesis. Mol Cell Biol 21:5063-5070.

Felsher DW, Zetterberg A, Zhu J, Tlsty T, and Bishop JM (2000). Overexpression of MYC causes p53-dependent G2 arrest of normal fibroblasts. Proc Natl Acad Sci USA 97: 10544-10548.
Fulda S, Lutz W, Schwab M, and Debatin KM (1999). MycN sensitizes neuroblastoma cells for drug-induced apoptosis. Oncogene 18:1479-1486.

Gerbitz A, Mautner J, Geltinger C, Hortnagel K, Christoph B, Asenbauer H, Klobeck G, Polack A, and Bornkamm GW (1999). Deregulation of the proto-oncogene c-myc through $\mathrm{t}(8 ; 22)$ translocation in Burkitt's lymphoma. Oncogene 18: 1745-1753.

Gibson UE, Heid CA, and Williams PM (1996). A novel method for real time quantitative RT-PCR. Genome Res 6:995-1001.

Gregory MA and Hann SR (2000). c-Myc proteolysis by the ubiquitin-proteasome pathway: Stabilization of c-Myc in Burkitt's lymphoma cells. Mol Cell Biol 20:2423-2435.

Greil R, Fasching B, Loidl P, and Huber H (1991). Expression of the c-myc proto-oncogene in multiple myeloma and chronic lymphocytic leukemia: An in situ analysis. Blood 78:180-191.

Guo QM, Malek RL, Kim S, Chiao C, He M, Ruffy M, Sanka K, Lee NH, Dang CV, and Liu ET (2000). Identification of c-myc responsive genes using rat cDNA microarray. Cancer Res 60:5922-5928.

Heid CA, Stevens J, Livak KJ, and Williams PM (1996). Real time quantitative PCR. Genome Res 6:986-994.

Hernandez L, Hernandez S, Bea S, Pinyol M, Ferrer A, Bosch F, Nadal A, Fernandez PL, Palacin A, Montserrat E, and Campo E (1999). c-myc mRNA expression and genomic alterations in mantle cell lymphomas and other nodal nonHodgkin's lymphomas. Leukemia 13:2087-2093.

Jack AS, Kerr IB, Evan G, and Lee FD (1986). The distribution of the c-myc oncogene product in malignant lymphomas and various normal tissues as demonstrated by immunocytochemistry. Br J Cancer 53:713-719.

Jaffe ES, Harris NL, Stein H, and Vardiman JW. (2001). Pathology and genetics of tumours of haematopoietic and lymphoid tissues. World Health Organization classification of tumours. Lyon: IARC Press.

Ji L, Arcinas M, and Boxer LM (1994). NF-kappa B sites function as positive regulators of expression of the translocated c-myc allele in Burkitt's lymphoma. Mol Cell Biol 14:7967-7974.

Kanda K, Hu HM, Zhang L, Grandchamps J, and Boxer LM (2000). NF-kappa B activity is required for the deregulation of c-myc expression by the immunoglobulin heavy chain enhancer. J Biol Chem 275:32338-32346.

Khaira P, James CD, and Leffak M (1998). Amplification of the translocated c-myc genes in three Burkitt lymphoma cell lines. Gene 211:101-108.

Kramer MH, Hermans J, Wijburg E, Philippo K, Geelen E, van Krieken JH, de Jong D, Maartense E, Schuuring E, and Kluin PM (1998). Clinical relevance of BCL2, BCL6, and MYC rearrangements in diffuse large B-cell lymphoma. Blood 92:3152-3162.

Latil A, Vidaud D, Valeri A, Fournier G, Vidaud M, Lidereau R, Cussenot O, and Biache I (2000). htert expression correlates with MYC over-expression in human prostate cancer. Int $\mathrm{J}$ Cancer 89:172-176.

Lin Y, Wong K, and Calame K (1997). Repression of c-myc transcription by Blimp-1, an inducer of terminal B cell differentiation. Science 276:596-599. 
Loke SL, Neckers LM, Schwab G, and Jaffe ES (1988). c-myc protein in normal tissue. Effects of fixation on its apparent subcellular distribution. Am J Pathol 131:29-37.

Madisen L and Groudine M (1994). Identification of a locus control region in the immunoglobulin heavy-chain locus that deregulates c-myc expression in plasmacytoma and Burkitt's lymphoma cells. Genes Dev 8:2212-2226.

Nasi S, Ciarapica R, Jucker R, Rosati J, and Soucek L (2001). Making decisions through Myc. FEBS Lett 490:153-162.

Neiman PE, Ruddell A, Jasoni C, Loring G, Thomas SJ, Brandvold KA, Lee R, Burnside J, and Delrow J (2001). Analysis of gene expression during myc oncogene-induced lymphomagenesis in the bursa of Fabricius. Proc Natl Acad Sci USA 98:6378-6383.

Nesbit CE, Tersak JM, Grove LE, Drzal A, Choi H, and Prochownik EV (2000). Genetic dissection of c-myc apoptotic pathways. Oncogene 19:3200-3212.

Nesbit CE, Tersak JM, and Prochownik EV (1999). MYC oncogenes and human neoplastic disease. Oncogene 18: 3004-3016.

O'Hagan RC, Ohh M, David G, de Alboran IM, Alt FW, Kaelin WG Jr, and DePinho RA (2000). Myc-enhanced expression of Cul1 promotes ubiquitin-dependent proteolysis and cell cycle progression. Genes Dev 14:2185-2191.

Pagnano KB, Vassallo J, Lorand-Metze I, Costa FF, and Saad ST (2001). p53, Mdm2, and c-Myc overexpression is associated with a poor prognosis in aggressive non-Hodgkin's lymphomas. Am J Hematol 67:84-92.

Pasqualucci L, Neumeister P, Goossens T, Nanjangud G, Chaganti RS, Kuppers R, and Dalla-Favera R (2001). Hypermutation of multiple proto-oncogenes in B-cell diffuse largecell lymphomas. Nature 412:341-346.

Perez-Roger I, Kim SH, Griffiths B, Sewing A, and Land H (1999). Cyclins D1 and D2 mediate myc-induced proliferation via sequestration of p27(Kip1) and p21(Cip1). EMBO J 18: 5310-5320.

Rao PH, Houldsworth J, Dyomina K, Parsa NZ, Cigudosa JC, Louie DC, Popplewell L, Offit K, Jhanwar SC, and Chaganti RS (1998). Chromosomal and gene amplification in diffuse large B-cell lymphoma. Blood 92:234-240.

Saez A, Sanchez E, Sanchez-Beato M, Cruz MA, Chacon I, Munoz E, Camacho FI, Martinez-Montero JC, Mollejo M, Garcia JF, and Piris MA (1999). p27KIP1 is abnormally expressed in diffuse large B-cell lymphomas and is associated with an adverse clinical outcome. Br J Cancer 80:14271434.

Sanchez-Beato M, Camacho FI, Martinez-Montero JC, Saez Al, Villuendas R, Sanchez-Verde L, Garcia JF, and Piris MA (1999). Anomalous high p27/KIP1 expression in a subset of aggressive B-cell lymphomas is associated with cyclin D3 overexpression. p27/KIP1-cyclin D3 colocalization in tumor cells. Blood 94:765-772.

Sanchez-Beato M, Saez Al, Navas IC, Algara P, Sol Mateo M, Villuendas R, Camacho F, Sanchez-Aguilera A, Sanchez E, and Piris MA (2001). Overall survival in aggressive B-cell lymphomas is dependent on the accumulation of alterations in p53, p16, and p27. Am J Pathol 159:205-213.
Schmitt CA, McCurrach ME, de Stanchina E, WallaceBrodeur RR, and Lowe SW (1999). INK4a/ARF mutations accelerate lymphomagenesis and promote chemoresistance by disabling p53. Genes Dev 13:2670-2677.

Schuhmacher M, Kohlhuber F, Holzel M, Kaiser C, Burtscher H, Jarsch M, Bornkamm GW, Laux G, Polack A, Weidle UH, and Eick $D$ (2001). The transcriptional program of a human $B$ cell line in response to Myc. Nucleic Acids Res 29:397-406.

Shaffer AL, Rosenwald A, Hurt EM, Giltnane JM, Lam LT, Pickeral OK, and Staudt LM (2001). Signatures of the immune response. Immunity 15:375-385.

Shaffer AL, Yu X, He Y, Boldrick J, Chan EP, and Staudt LM (2000). BCL-6 represses genes that function in lymphocyte differentiation, inflammation, and cell cycle control. Immunity 13:199-212.

Teitz T, Wei T, Valentine MB, Vanin EF, Grenet J, Valentine VA, Behm FG, Look AT, Lahti JM, and Kidd VJ (2000). Caspase 8 is deleted or silenced preferentially in childhood neuroblastomas with amplification of MYCN. Nat Med 6:529-535.

The International Non-Hodgkin's Lymphoma Prognostic Factors Project (1993). A predictive model for aggressive nonHodgkin's lymphoma. N Engl J Med 329:987-994.

Villuendas R, Pezzella F, Gatter K, Algara P, Sanchez-Beato M, Martinez P, Martinez JC, Munoz K, Garcia P, Sanchez L, Kocialkowsky S, Campo E, Orradre JL, and Piris MA (1997). p21WAF1/CIP1 and MDM2 expression in non-Hodgkin's lymphoma and their relationship to p53 status: a p53+, MDM2-, p21-immunophenotype associated with missense p53 mutations. J Pathol 181:51-61.

Vitolo U, Gaidano G, Botto B, Volpe G, Audisio E, Bertini M, Calvi R, Freilone R, Novero D, Orsucci L, Pastore C, Capello D, Parvis G, Sacco C, Zagonel V, Carbone A, Mazza U, Palestro G, Saglio G, and Resegotti L (1998). Rearrangements of bcl-6, bcl-2, c-myc and $6 \mathrm{q}$ deletion in B-diffuse large-cell lymphoma: Clinical relevance in 71 patients. Ann Oncol 9:55-61.

Wagner AJ, Kokontis JM, and Hay N (1994). Myc-mediated apoptosis requires wild-type p53 in a manner independent of cell cycle arrest and the ability of p53 to induce p21waf1/ cip1. Genes Dev 8:2817-2830.

Wittekindt NE, Hortnagel K, Geltinger C, and Polack A (2000). Activation of c-myc promoter P1 by immunoglobulin kappa gene enhancers in Burkitt lymphoma: Functional characterization of the intron enhancer motifs kappaB, E box 1 and $\mathrm{E}$ box 2, and of the 3 ' enhancer motif PU. Nucleic Acids Res 28:800-808.

Yang W, Shen J, Wu M, Arsura M, FitzGerald M, Suldan Z, Kim DW, Hofmann CS, Pianetti S, Romieu-Mourez R, Freedman LP, and Sonenshein GE (2001). Repression of transcription of the p27(Kip1) cyclin-dependent kinase inhibitor gene by c-Myc. Oncogene 20:1688-1702. 